\title{
Can the Diverse Family of Dialysis Adequacy Indices Be Understood as One Integrated System?
}

\author{
Jacek Waniewski ${ }^{a, b}$ Malgorzata Debowska ${ }^{a}$ Bengt Lindholm ${ }^{b}$ \\ anstitute of Biocybernetics and Biomedical Engineering, Warsaw, Poland; ${ }^{\mathrm{b}}$ Divisions of Baxter Novum and Renal \\ Medicine, Department of Clinical Sciences, Intervention and Technology, South University Huddinge Hospital, \\ Karolinska Institutet, Stockholm, Sweden
}

\section{Key Words}

Equivalent renal clearance - Solute removal index •

Fractional solute removal $\cdot$ Equivalent continuous

clearance $\cdot$ Kinetic modeling

\begin{abstract}
Background: Dialysis adequacy indices are based on the amount of removed solute and systemized into two groups: (1) fractional solute removal (FSR, non-dimensional), and (2) equivalent continuous clearance (ECC, $\mathrm{ml} / \mathrm{min}$ ), which are expressed using appropriate reference method for solute concentration or mass such as: peak, peak average, time average, and treatment time average values. Methods: A review and critical analysis of the recent studies was performed. Results: The indices are mathematically interrelated and depend on kinetic parameters of the treatment, as device clearance, treatment time, solute distribution volume, dialysis frequency. In particular, KT/V and KT can be directly translated to FSR and ECC using the treatment time average reference method. Conclusion: The diverse family of dialysis adequacy indices can be understood as one integrated system and be useful when assessing both standard treatment modalities and newer schedules and modalities (frequent dialysis, hybrid dialysis, dialysis in acute renal failure) of renal replacement therapies.

Copyright $\odot 2010$ S. Karger AG, Basel
\end{abstract}

\section{Introduction}

Methods to define the adequate 'dose' of dialysis have been debated from the beginning of this therapy. The initial empirical rules were tested in the US in the large-scale National Cooperative Dialysis Study (NCDS), where the average (per week) urea level was used as the treatment target in hemodialysis (HD) [1]. A subsequent 'mechanistic' analysis of the results of NCDS demonstrated that a simple nondimensional parameter - urea KT/V (urea dialyzer clearance $\mathrm{K}$ multiplied by treatment time $\mathrm{T}$ and divided by urea distribution volume $\mathrm{V}$ ) - should be higher than 0.8 (later increased to 1.0) to avoid increased mortality of dialyzed patients [2]. The application of KT/V based on urea kinetic modeling dominated studies of dialysis adequacy for more than 20 years. Its analogue was introduced for peritoneal dialysis (PD), where KT/V can be estimated directly from urea mass removed as measured in daily collections of spent peritoneal dialyzate [3].

More recent large-scale clinical studies on dialysis adequacy, as the HEMO study for HD and the ADEMEX study for PD, failed to demonstrate that increasing KT/V over the established level used in the clinic could decrease patient morbidity and improve survival $[4,5]$; however, this negative finding may depend on the assumptions used for statistical analysis. A new study showed no rela-

\section{KARGER}

Fax +4161306 1234 E-Mail karger@karger.ch www.karger.com

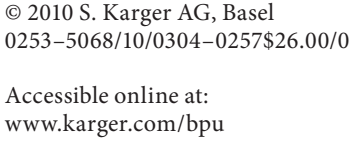

\footnotetext{
Jacek Waniewski

Institute of Biocybernetics and Biomedical Engineering

Trojdena 4

PL-02 109 Warszawa (Poland)

Tel. +48 22659 9143, Fax +48 22659 7030, E-Mail jacek.waniewski@ibib.waw.pl
} 
tionship between mortality and increase in dialysis dose if the standard proportional hazards method was applied, whereas a strong association between urea KT/V and mortality was found if the so-called accelerated failure time model was used [6]. On the other hand, clinical studies show that both $\mathrm{KT}$ and $\mathrm{V}$ are independent predictors of mortality, and the use of KT/V as a predictor of clinical outcome has been questioned as this index is the ratio of two predictors [7-9]. These findings and other discussions on dialysis adequacy turned the attention to other parameters which could be useful for defining the adequate dialysis dose, as equivalent continuous clearance (ECC, EKR), fractional solute removal (FSR, called also solute removal index, SRI), standardized $\mathrm{KT} / \mathrm{V}$, $\operatorname{stdKT} / \mathrm{V}$, and $\mathrm{KT}$ itself (without normalization to urea distribution volume) $[7,8,10-13]$.

In the present review, we discuss the relationships and differences between all these indices and show that they all in fact are specific variants within a well-characterized system of dialysis adequacy indices (DAI).

\section{Dialysis Adequacy Indices}

There are currently two major types of adequacy indices, and they may be applied for various solutes, including the standard markers of dialysis adequacy - urea and creatinine: (1) nondimensional index, fractional solute removal, FSR: based on the amount of solute removed per treatment cycle $\left(M_{R}\right)$ divided by the amount of this solute in the body $\left(\mathrm{M}_{\mathrm{B}}\right)$, and (2) equivalent continuous clearance, ECC: measured in units of clearance, e.g. $\mathrm{ml} / \mathrm{min}$, which represents the hypothetical continuous clearance of the solute that would result in the removal of the same amount of the solute as the actual, often intermittent treatment during the treatment cycle. ECC is generally different from the clearance $\mathrm{K}$ of the device (or treatment), which is defined as the amount of solute removed during time $\mathrm{T}$ of the effective treatment divided by $\mathrm{T}$ and the average solute concentration in plasma during time $\mathrm{T}$. In particular, for hemodialysis $\mathrm{K}$ is equal to the effective clearance of dialyzer.

The treatment cycle is considered here as the treatment schedule that is repeated without any modifications; for standard HD, the treatment cycle is based on three consecutive dialysis sessions during 1 week, whereas for PD the natural treatment cycle is 1 day with a few exchanges of dialysis fluid. The treatment cycle may, however, be extended over the natural unit, as for example for peritoneal dialysis the cycle may be defined as one week to make the comparison with hemodialysis adequacy indices easier.

The above description of FSR and ECC is directly applicable only for continuous (or quasi-continuous) treatments, as continuous ambulatory peritoneal dialysis (CAPD), which is characterized by constant (or practically constant) concentration and amount of the solute in the body. However, for intermittent treatments, such as hemodialysis, the solute concentration, body water volume, and solute amount in the body vary during the treatment cycle, and therefore one has to decide which reference value of the solute concentration, amount, and distribution volume are used in the definitions of DAI.

A few types of different reference values have been proposed:

(1) the peak value during treatment cycle [11],

(2) the peak average value for treatment cycle, e.g. the average of three consecutive pre-dialysis urea concentrations during the standard thrice weekly HD [14],

(3) the time average for treatment cycle, e.g. the weekly average of urea concentration [10],

(4) the treatment time average for treatment cycle, e.g. the average urea concentration during the effective dialysis time for three consecutive dialysis sessions in standard thrice weekly HD regime [15].

One can also discuss other types of reference methods, as for example the minimum value [15], but their practical clinical applications and implications have not yet been explored systematically.

Thus, we may formulate more precise definitions of FSR and ECC using the notation 'ref' for each of the following indexes denoting reference methods: $p=$ peak value, $\mathrm{pa}=$ peak average value, $\mathrm{ta}=$ time average value, trta $=$ treatment time average value:

(1) Nondimensional index, fractional solute removal, FSR $_{\text {ref, }}$ is equal to the amount of solute removed per treatment cycle $\left(M_{R}\right)$ divided by the reference amount of this solute in the body $\left(\mathrm{M}_{B}\right.$, ref $)$ :

$\mathrm{FSR}_{\mathrm{ref}}=\frac{\mathrm{M}_{\mathrm{R}}}{\mathrm{M}_{\mathrm{B}, \mathrm{ref}}}$

(2) Equivalent continuous clearance, $\mathrm{ECC}_{\mathrm{ref}}$, is the hypothetical continuous clearance of the solute that would result in the removal of the same amount of the solute $\left(\mathrm{M}_{\mathrm{R}}\right)$ as the actual, often intermittent treatment during the treatment cycle $\left(\mathrm{T}_{\mathrm{C}}\right)$, and the constant reference solute concentration in the body $\left(\mathrm{C}_{\mathrm{ref}}\right)$ :

$$
\mathrm{ECC}_{\text {ref }}=\frac{\mathrm{M}_{\mathrm{R}} / \mathrm{T}_{\mathrm{C}}}{\mathrm{C}_{\mathrm{ref}}}
$$


Table 1. The system of dialysis adequacy indices including the two groups, FSR and ECC, and the four different reference methods with the specific names for the indices used in the current literature on dialysis adequacy

\begin{tabular}{lll}
\hline $\begin{array}{l}\text { Reference method } \\
\text { (mass/concentration) }\end{array}$ & $\begin{array}{l}\text { Fractional solute } \\
\text { removal } \\
\text { FSR }=\mathrm{M}_{\mathrm{R}} / \mathrm{M}_{\mathrm{B}} \\
\text { nondimensional }\end{array}$ & $\begin{array}{l}\text { Equivalent contin- } \\
\text { uous clearance } \\
\mathrm{ECC}=\mathrm{M}_{\mathrm{R}} /\left(\mathrm{T}_{\mathrm{C}} \mathrm{C}_{\mathrm{B}}\right) \\
\mathrm{ml} / \mathrm{min}\end{array}$ \\
\hline $\begin{array}{l}\text { Peak } \\
\text { Peak average }\end{array}$ & $\mathrm{FSR}(\mathrm{SRI})$ & $\mathrm{NN}$ \\
$\begin{array}{l}\text { Time average } \\
\text { Treatment time average }\end{array}$ & $\mathrm{NNT} / \mathrm{st}$ & $\mathrm{stK}$ \\
$\mathrm{NKR}$ & $\mathrm{KT} / \mathrm{T}_{\mathrm{C}}$
\end{tabular}

$\mathrm{T}=$ Total treatment time during one dialysis cycle of duration $\mathrm{T}_{\mathrm{C}}$ (typically, $\mathrm{T}_{\mathrm{C}}$ is 1 week); $\mathrm{NN}=$ no specific name was proposed for this parameter.

With the definition of two types of DAI and four reference methods for each type, eight possible variants of DAI appear (table 1). All DAI proposed by different authors can be placed within this table, although some adjustments and clarifications of their definitions may be required as discussed below. Note that two 'empty' cells in table 1 do not have any specific name for the respective DAI, but each of these two DAI is also a possible choice for practical application.

\section{$K T / V$}

This parameter which since long has been a subject of many controversies and discussions [16-21] is often described as 'fractional urea clearance' [22]. This description is obvious for peritoneal dialysis where KT/V calculated as the urea amount removed from the body over the urea amount in the body, can be easily measured from: daily collections of spent dialysate and urine, measured urea level in plasma, and estimations of total body water [3]. (Note that the word 'fractional' is used here in its general meaning as the ratio of two numbers and not necessarily being less than one.) This means that ' $\mathrm{KT} / \mathrm{V}$ ' in peritoneal dialysis is actually defined and measured as FSR (see above). For HD, the definition of KT/V is based on a different concept and its evaluation needs to be carried out using urea kinetic modeling, although a common perception of KT/V in HD is that it is a kind of FSR. Not only the theoretical meaning but also the practical meaning of $\mathrm{KT} / \mathrm{V}$ in $\mathrm{HD}$ and $\mathrm{PD}$ is quite different $[15,23]$. In $\mathrm{HD}$, $\mathrm{KT} / \mathrm{V}$ is, in addition to being a tool for evaluation of dialysis adequacy, an operational parameter that allows for easy planning of dialysis treatment to obtain the target value of $\mathrm{KT} / \mathrm{V}$. In contrast, KT/V in PD is mainly an observational parameter that can be used for assessment of adequacy but cannot be directly used for the precise planning of the treatment, unless PD kinetic modeling is applied [23]. The theoretical basis for such divergent applications of KT/V is the concept of the water volume that is cleared from urea (as measured by KT) normalized to the total body water (V). However, the total body water, urea concentration, and therefore the urea mass in the body vary during intermittent treatments, and, although this simple fact is often neglected, it is clear that we need to carefully consider which type of reference method to use. In particular, it can be shown that FSR calculated using the treatment time average urea mass in the body is equal to $\mathrm{KT} / \mathrm{V}_{\text {trta }}$, where $\mathrm{V}_{\text {trta }}$ is defined as the treatment time average distribution volume, $\mathrm{V}_{\text {trta }}=\mathrm{M}_{\text {trta }} / \mathrm{C}_{\text {trta }}$ (table 1). (Whereas this can be said to be an artificial definition of $\mathrm{V}$, it allows for a more precise definition of $\mathrm{KT} / \mathrm{V}$ as a real measure of urea removal.)

\section{KT}

This parameter, meaning dialyzer clearance of urea multiplied by the treatment time, was proposed to be used instead of KT/V based on clinical studies showing that $\mathrm{KT}$ is an independent predictor of patient mortality [8]. Its definition suggests that it is related to the treatment time reference method. Actually, after normalizing $\mathrm{KT}$ to the treatment cycle time $\mathrm{T}_{\mathrm{C}}$, which is typically a fixed parameter when reporting outcomes of clinical studies, one finds that $\mathrm{KT}$ is a specific form of expressing equivalent continuous clearance for the treatment time reference method: $\mathrm{ECC}_{\text {trta }}=\mathrm{KT} / \mathrm{T}_{\mathrm{C}}$ (table 1$)$.

Thus, the controversy 'KT/V' versus 'KT' reflects the difference between using FSR or ECC.

\section{EKR}

Equivalent renal clearance was historically the first DAI alternative to KT/V [10]. It was based on the time average urea concentration, thus continuing the NCDS approach to dialysis adequacy targeting [1], and got wide acceptance in both theoretical and clinical studies $[10,13$, $16,17,24-31]$. Obviously, EKR $=$ ECC $_{\text {ta. }}$.

\section{$F S R_{t a}$}

A specific case of FSR, related to EKR, not addressed yet in the literature.

\section{$s t d K T / V$}

Standardized KT/V, defined as FSR using the peak average value as reference method was introduced as an al- 
ternative DAI based on the argument that its values for typical HD are similar to those for typical CAPD, and therefore stdKT/V might be used for comparison of these two treatments [14].

\section{$s t d K$}

This parameter, when using the peak average urea concentration, is a specific case of ECC [14].

\section{FSR or SRI}

Fractional solute removal (FSR) was defined as $\mathrm{FSR}_{\mathrm{p}}$ $[11,32]$. Nowadays, it is often referred to as solute removal index (SRI), although the initial definition of SRI was different and involved the removed urea mass minus the urea mass generated during the treatment instead of just the removed urea mass as in FSR [12]. This first definition of SRI could of course be used only for one dialysis session, because for the treatment cycle SRI was always equal to zero if the patient was in metabolically stable state. Therefore, the definition of SRI was changed to that used for FSR, although the name SRI continued to be used.

\section{$E C C_{p}$}

This specific case of ECC, related to FSR/SRI, has not yet been used in any clinical study.

Different names were proposed for specific DAI when they were introduced for the first time, and therefore it may difficult to recognize that they can be arranged in a logical manner using a table like table 1 and a simple nomenclature based on only two principles:

(1) The type of parameter, i.e. FSR or ECC.

(2) The type of reference method (i.e. p, pa, ta, trta values)

for the solute mass (for FSR) or solute concentration (for ECC).

The adequacy indices are based on the removed mass and the solute concentration in plasma (that for small solutes is equal to the concentration in the extracellular compartment), i.e. the compartment which is directly cleared by dialysis. However, DAI depend implicitly on the solute generation rate in the body, because the solute concentration in plasma (and its total amount in the body) throughout the dialysis cycle depends on its generation rate besides the removal rate. Furthermore, the removal of the solute also depends on its concentration in plasma, and therefore on its generation rate. Although the initial formula for $\mathrm{KT} / \mathrm{V}$ calculated for one dialysis session assumed the generation rate as negligible (what may be a reasonable approximation for a short and highly efficient dialysis session), the modern formulae for KT/V include the correction for the generation rate even for one dialysis session $[13,33]$. It is also worth mentioning that the definition of clearance always includes the solute concentration in the directly cleared compartment (mostly plasma), so this concentration is also used in the definitions of DAI [28, discussion].

The adequacy indices have been applied mostly for urea, but also sometimes for creatinine, and occasionally for beta-2-microglobulin [31]. For urea and creatinine it is rather obvious how to define their distribution volumes and subcompartments, although the practical estimation of these volumes is subject to many discussions and involves approximations [34-36]. However, the adequacy indices may be used also for any other solute that is removed during dialysis, as uric acid, sodium, potassium, phosphate, calcium, magnesium, or absorbed during dialysis, as glucose in peritoneal dialysis, lactate, bicarbonate (the value of the indices for absorbed solutes are formally negative). The distribution volume and the exchangeable mass for some of these solutes are difficult to define precisely (think, for example, about calcium and phosphate), the transport processes between internal compartments are nonlinear (sodium, potassium, and most ions), and therefore kinetic modeling of their transport during dialysis is more challenging than for urea and creatinine. It may be difficult to assess their FSR indices in clinical studies, because the body mass of these solutes is not easy to be determined. On the contrary, ECC indices are always measurable because only the removed mass and plasma concentration profiles need to be determined. The most accurate approach to the evaluation of DAI consists in the collection of spent dialyzate and frequent measurements of solute concentration in plasma; however, it is not clinically feasible for the large scale and therefore kinetic modeling may be helpful for the estimation of DAI in the same way for the estimation of KT/V for urea [13, 33]. The modeling itself, although its theoretical basis and mathematical methods are well known, should be applied carefully for real clinical studies, because some corrections must be taken into account, as for example the access and cardiopulmonary recirculation in the relationship between the dialyzer clearance and the 'kinetic' clearance that describes (and can be estimated from) the rate of the decrease of solute concentration in plasma [37]. Furthermore, one should remember that the physiology of solute distribution in the body may need to take into account the difference in perfusion of different organs, as in the regional blood flow model for urea and creatinine [37, 38]. These problems are related to practical methods for the estimation of DAI and do not have any direct effect on their definitions that are discussed in this review. 


\section{Relationships between Different DAI}

ECC and FSR are related by a simple mathematical equation:

$\mathrm{ECC}=\mathrm{FSR} \cdot \mathrm{V} / \mathrm{T}_{\mathrm{C}}$

or, in another way:

$\mathrm{FSR}=\mathrm{ECC} /\left(\mathrm{V} / \mathrm{T}_{\mathrm{C}}\right)$

where all variables FSR, ECC and V are calculated using the same reference method. The ratio $\mathrm{ECC}_{\text {ref }} / \mathrm{FSR}_{\text {ref }}=$ $\mathrm{V}_{\text {ref }} / \mathrm{T}_{\mathrm{C}}$ may vary slightly between different reference methods (table 2)

Thus, ECC and FSR can be mutually recalculated from each other using a parameter with the clearance unit that may be called the reference continuous clearance, RCC = $\mathrm{V} / \mathrm{T}_{\mathrm{C}}$, dependent only on the size of the patient, represented by $\mathrm{V}$, and the treatment cycle time, $\mathrm{T}_{\mathrm{C}}$. In particular, if RCC = ECC then FSR = 1, which means that during one treatment cycle the removed solute mass is equal to the total body amount of this solute. RCC is related to the choice of the reference method. With the change in the treatment for a patient, if $\mathrm{V}$ does not change, the values of ECC and FSR may in general change, but their quotient, RCC, stays constant. The average values of these two different DAI in different patient populations cannot however be easily recalculated, because of the impact of the specific patient size distribution on the recalculation factor.

The choice between FSR and ECC as the DAI used for targeting dialysis dose has important consequences for the prescriptions of dialysis in patients with different body size (V). If FSR (KT/V) is targeted, then patients with lower $\mathrm{V}$ should get less dialysis as measured by KT (or ECC) than patients with large V. If, in contrast, ECC $\left(\mathrm{KT} / \mathrm{T}_{\mathrm{C}}\right)$ is targeted, patients with different body size should get the same dialysis dose measured by ECC, but different doses if measured by KT/V ( $\left.\mathrm{FSR}_{\text {trta }}\right)$, because $\mathrm{KT} / \mathrm{V}$ is higher for patients with lower V. So far, the relationship between mortality and dialysis adequacy was shown for both FSR (KT/V) and ECC $\left(\mathrm{KT} / \mathrm{T}_{\mathrm{C}}\right)$, but a detailed analysis of the possible differences between these two methods regarding their use for targeting the dialysis dose is still missing. However, underdialysis of patients with low $\mathrm{V}$, and in particular women, was found in some clinical trials $[39,40]$. These data may suggest that ECC provides a better target for dialysis than FSR, or, that KT should be scaled not using V but applying instead body surface area [41-43]. This scaling is currently being used for creatinine clearance (ECC) in peritoneal dialysis [44].

Dialysis Adequacy Indices
Table 2. Weekly ECC, FSR, the ratio of ECC to FSR, the solute distribution volume, $\mathrm{V}_{\text {ref }}$, and blood urea nitrogen concentration, $\mathrm{C}_{\mathrm{ref}}$, calculated according to four different definitions, peak (p), peak average (pa), time average (ta), and treatment time average (trta), for hemodialysis carried out 3 times a week with short sessions, HD1, or 3 times a week with long sessions, HD2, or 6 times a week, HD3, with the same value of KT/V

\begin{tabular}{llrrlll}
\hline & & $\begin{array}{l}\text { ECC } \\
\text { ml/min }\end{array}$ & FSR & $\begin{array}{l}\text { ECC/FSR } \\
\text { ml/min }\end{array}$ & $\begin{array}{l}\mathrm{V}_{\text {ref }} \\
\text { liters }\end{array}$ & $\begin{array}{l}\mathrm{C}_{\text {ref }} \\
\mathrm{mg} / \mathrm{ml}\end{array}$ \\
\hline $\mathrm{HD1}$ & $\mathrm{p}$ & 6.59 & 1.70 & 3.88 & 39.13 & 1.06 \\
$\mathrm{KT} / \mathrm{V}=3.6$ & $\mathrm{pa}$ & 7.36 & 1.94 & 3.79 & 38.17 & 0.95 \\
& ta & 10.21 & 2.78 & 3.67 & 36.99 & 0.69 \\
& trta & 12.80 & 3.02 & 4.24 & 42.79 & 0.55 \\
\hline $\mathrm{HD} 2$ & $\mathrm{p}$ & 6.86 & 1.77 & 3.87 & 38.99 & 1.02 \\
$\mathrm{KT} / \mathrm{V}=3.6$ & $\mathrm{pa}$ & 7.72 & 2.05 & 3.77 & 38.04 & 0.91 \\
& ta & 10.82 & 2.95 & 3.66 & 36.93 & 0.65 \\
& trta & 12.82 & 3.20 & 4.00 & 40.32 & 0.55 \\
\hline $\mathrm{HD} 3$ & $\mathrm{p}$ & 7.54 & 2.02 & 3.74 & 37.71 & 0.93 \\
$\mathrm{KT} / \mathrm{V}=3.6$ & $\mathrm{pa}$ & 8.92 & 2.47 & 3.62 & 36.46 & 0.78 \\
& ta & 10.80 & 3.02 & 3.57 & 36.01 & 0.65 \\
& trta & 12.80 & 3.13 & 4.08 & 41.17 & 0.55 \\
\hline
\end{tabular}

The results were obtained using the variable-volume twocompartment model with total postdialysis distribution volume $\mathrm{V}=35$ liters and urea generation rate $\mathrm{G}=7 \mathrm{mg} / \mathrm{min}$. Dialyzer clearances were selected according to the fixed value of $\mathrm{KT} / \mathrm{V}=$ 3.6 for all three schedules.

The choice of reference method has been debated for long, at least from the time when the time average concentration and peak concentration hypotheses were formulated and debated [45]. Nowadays, more options are available, with peak average concentration and treatment time average concentration being added to the arsenal of reference methods $[14,15,23]$. In particular, KT/V which dominated the whole area of hemodialysis adequacy for long time, and $\mathrm{KT}$, are in fact both based on the treatment time average option $[15,23]$.

\section{Relationships between DAI and Transport Parameters}

The details of the solute kinetics during HD sessions and peritoneal dialysis dwells can in practice be assessed only by applying computer modeling. However, an insight into the problem of the relationships between DAI and the parameters that describe the rate of the solute removal and the final result of the treatment may be ob- 
tained using a simple one-compartment model with constant distribution volume and a single treatment session that may be periodically repeated. Actually, the origin of the KT/V concept was based on this kind of simplified modeling that is still often referred to for the sake of education [33]. Using this simplification one can describe both FSR and ECC by closed analytical formulas that include the following three scaled parameters [28]:

(1) $\mathrm{k}=\mathrm{KT} / \mathrm{V}$, which has a well-known interpretation and application for $\mathrm{HD}$; however, $\mathrm{K}$ in $\mathrm{PD}$ denotes the diffusive mass area transport parameter, $\mathrm{K}_{\mathrm{BD}}$ (also called MTAC, or PS $[15,23])$,

(2) $\theta=T / T_{C}$, which is the real treatment time divided by the treatment cycle time,

(3) $\mathrm{v}=\mathrm{V}_{\mathrm{D}} /\left(\mathrm{V}+\mathrm{V}_{\mathrm{D}}\right)$, where $V_{D}$ is the volume of dialysis fluid that is used during the treatment; this parameter is crucial for $\mathrm{PD}$ with $\mathrm{V}_{\mathrm{D}}$ being the infused volume of dialysis fluid, whereas $v=1$ in HD, because of the unlimited amount of fluid that can be used (i.e. no accumulation of the solute in fresh dialysis fluid).

FSR $_{\mathrm{p}}$ can be described using the above-defined three parameters as follows [28]:

$$
\mathrm{FSR}_{\mathrm{p}}=\mathrm{kv} \frac{1-\mathrm{e}^{-\mathrm{k} / \mathrm{v}}}{\mathrm{k}(1-\mathrm{v} \theta)+\mathrm{v}^{2} \theta\left(1-\mathrm{e}^{-\mathrm{k} / \mathrm{v}}\right)}
$$

This formula is valid for $\mathrm{HD}, \mathrm{PD}$ and other treatments (including for example continuous venovenous hemodialysis, CVVHD). A similar, albeit more sophisticated, formula can be derived for $\mathrm{ECC}_{\mathrm{ta}}[28]$ and other DAI. A particular case for HD reads:

$$
\mathrm{FSR}_{\mathrm{P}}=\mathrm{k} \frac{1-\mathrm{e}^{-\mathrm{k}}}{\mathrm{k}(1-\theta)+\theta\left(1-\mathrm{e}^{-\mathrm{k}}\right)}
$$

One can easily see that $\mathrm{FSR}_{\mathrm{p}}$ for $\mathrm{HD}$ depends on both $\mathrm{k}(\mathrm{KT} / \mathrm{V})$ and $\theta\left(\mathrm{T} / \mathrm{T}_{\mathrm{C}}\right)$, i.e. also on the treatment cycle time. Only for short dialysis sessions (i.e. low value of $\theta$ ) one can get:

$\mathrm{FSR}_{\mathrm{P}}=1-\mathrm{e}^{-\mathrm{k}}$

and only for continuous treatments ( $\theta$ equal to one) and the supply of fresh dialysis fluid: $\mathrm{FSR}_{\mathrm{p}}=\mathrm{KT} / \mathrm{V}$. Note however that $\mathrm{FSR}_{\text {trta }}=\mathrm{KT} / \mathrm{V}_{\text {trta }}$ for all treatment modalities.

Thus, the relationship between KT/V and the real fractional urea removal rate is not so straightforward, and the targets set up for KT/V may be different if related to FSR. For example, the increase of KT/V (FSR trta $)$ by $32 \%$ in the intervention group compared to the control group in the HEMO study was equivalent to an increase of FSR $\mathrm{ta}_{\mathrm{ta}}$ by $25 \%$ and of FSR $\mathrm{pa}$ (stdKT/V) by $16 \%$, as shown by computer-based analysis [15].

\section{Change of Dialysis Dose}

The relationship between clinical outcomes (such as mortality and morbidity) and changes in dialysis dose within a given population, or between patient groups with different dialysis doses, have been addressed by many clinical studies such as the above-mentioned NCDS, HEMO, ADEMEX studies, and the Frequent Hemodialysis Network (FHN) randomized trials, to mention only the large-scale ones $[1,4,5,46]$. The NCDS studies defined patients groups by targeting the time average urea concentration in plasma $\left(\mathrm{C}_{\mathrm{ta}}\right)$, whereas the later studies applied urea KT/V targets.

An important, but often neglected, problem is how changes in dialysis dose and in the respective DAI correlate to the changes in urea concentration in blood. Let us consider at first the case when urea generation rate is not influenced by the change in dialysis dose. Then, urea concentration in plasma is typically decreased following an increase in dialysis dose. However, there is a simple numerical relationship between urea concentration in plasma and DAI: $\mathrm{C}_{\text {ref }}$ is strictly reciprocal to $\mathrm{ECC}_{\text {ref }}$, as follows from the formula $\mathrm{C}_{\text {ref }}=\mathrm{G} / \mathrm{ECC}_{\text {ref. }}$. The similar statement is also valid for FSR if, in addition to no change in urea generation rate, there is also no difference in total body water after the modification of dialysis dose: $\mathrm{C}_{\text {ref }}=$ $\mathrm{G} \cdot \mathrm{T}_{\mathrm{C}} /\left(\mathrm{V}_{\text {ref }} \mathrm{FSR}_{\text {ref }}\right)$. Therefore, assuming no difference in the metabolism and hydration status of patients, the evaluation of the treatment using DAI or using DAI for targeting of therapy is equivalent to the assessment or targeting of the respective (by reference method) urea concentration in plasma.

A similar conclusion can be made for the comparison of DAI between study groups with different dialysis dose in cross-sectional studies. If the evaluation is performed in metabolic steady-state patients and there is no difference in the average urea generation rate between the study groups, then the comparison of DAI can be replaced by the comparison of the respective urea concentrations in plasma.

Only if the generation rate (and/or hydration status) is changed after the change of dialysis dose in a population of patients or if it differs between the study groups with different dialysis dose, then the difference in DAI cannot be directly translated into the difference in urea concentration in plasma. The condition for the equivalence between DAI and solute concentrations is valid for solutes other than urea but may differ from solute to solute, as exemplified by urea and creatinine that have different metabolic origin. 


\section{Time and Frequency of Dialysis}

The adequate duration of the individual dialysis session and treatment hours per week was discussed from the onset of highly efficient dialysis that allowed for considerable shortening of dialysis session. The patient survival data from the centers that continued the long, low-efficiency dialysis were consistently better than those from centers with short dialysis time [47]. The increased interest in daily dialysis and especially daily long night dialysis has renewed the discussion about adequate timing and frequency of dialysis sessions $[48,49]$. Many factors may be responsible for the reported better clinical outcomes in patients on long and/or more frequent dialysis sessions, including better cardiovascular stability, less variation in the level of uremic toxins, higher removal of phosphate and others [50, 51]. Ureabased DAI can only partially and indirectly predict the clinical effects of changes in duration and frequency of dialysis sessions.

The results of computer simulations of three different hemodialysis schedules with the same weekly KT/V = 3.6 each $(\mathrm{K}=$ effective dialyzer clearance, $\mathrm{T}=$ time of dialysis sessions per week, $\mathrm{V}$ = postdialysis total body water) for a typical patient are shown in table 2 and figure 1 (cf. [15]). The schedule HD1 was based on three dialysis sessions per week, the schedule HD2 comprised three long dialysis sessions per week, and the schedule HD3 - six daily short dialysis sessions per week [15]. The simulations were performed using the variable-volume, two-compartment urea kinetic model [15]. The total amount of urea removed by hemodialysis was the same for all three dialysis schedules. The time average and treatment time average urea concentration differed only slightly between the schedules; however, considerable differences were obtained for peak and peak average concentration values (table 2, fig. 1). The difference in urea concentration was reflected reciprocally by DAI (table 2 ). Similar observations were obtained when EKR and stdKT/V were compared by other computer simulations $[52,53]$. The peak average reference method seems to be more sensitive than the time average reference method to the change of frequency and time of dialysis while $\mathrm{KT} / \mathrm{V}$ is similar and therefore the peak average-based DAI may better correspond to the improved clinical outcomes with long and/ or frequent dialysis.

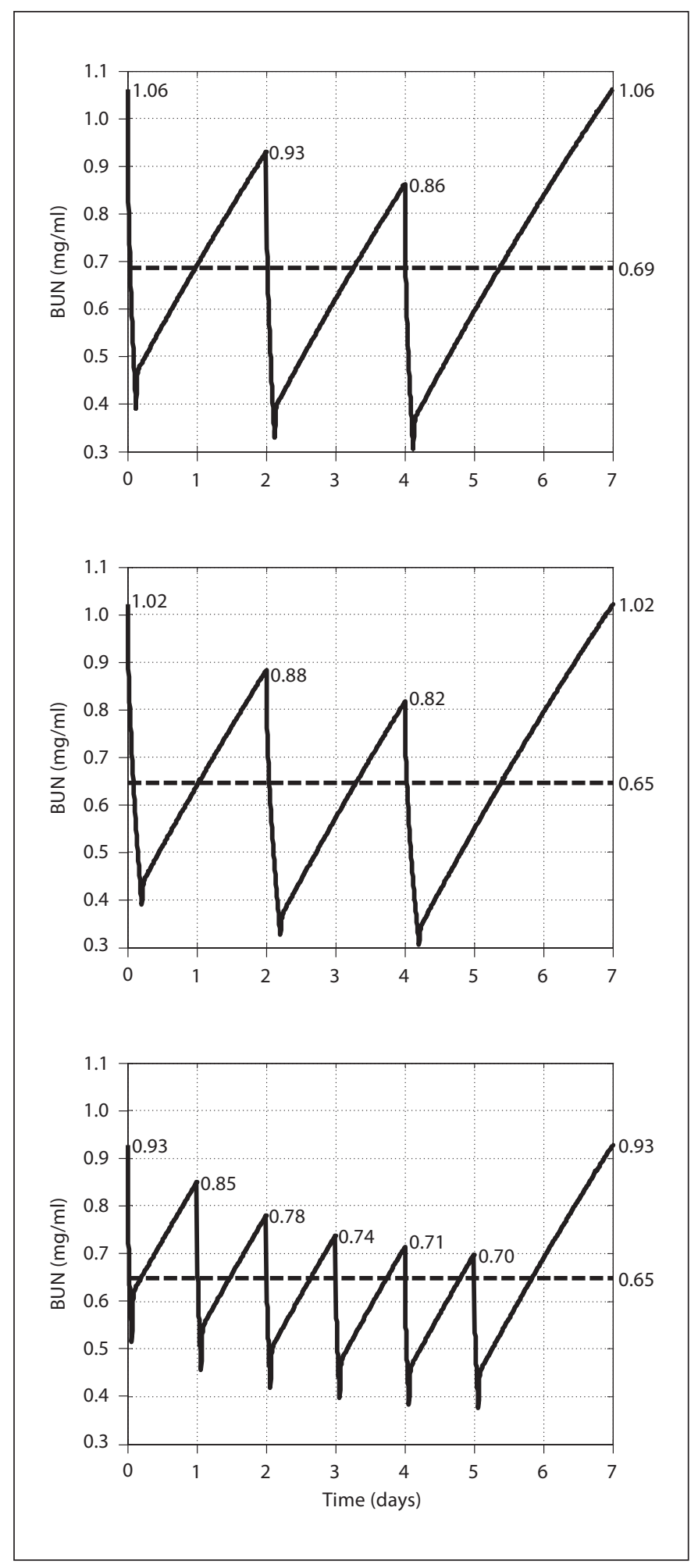

Fig. 1. Blood (extracellular) urea nitrogen (BUN) concentration profiles for the hemodialysis schedule with 3 dialysis sessions per week (HD1), 3 times a week with long sessions (HD2), and 6 short daily dialysis sessions per week (HD3) with the same weekly urea $\mathrm{KT} / \mathrm{V}=3.6$. 


\section{Conclusion}

The proposed unified approach for the definition and mathematical and practical evaluation of dialysis adequacy indices is valid for all modalities of dialysis applied for treatment of end-stage renal disease and acute renal failure patients. Thus, KT/V, ECC and FSR can be considered as variants within an integrated family of different dialysis adequacy indices of solute removal in relation to a set of defined solute reference concentrations (for ECC) or masses (for FSR). There are strict mathematical relationships - when using the same reference method - between these indices themselves, as well as between the indices and kinetic parameters of the treatment. However, the choice of the specific index to be used in clinical practice or in research cannot be made based only on theoretical considerations. Instead, other factors play an important role such as technology, practicality, acceptance and tradition. Ideally, the choice between the different indices should be based on the predictive power for mortality and morbidity of the specific index in systematic longitudinal observational - or even better - interventional clinical studies of clinical outcomes in relation to dialysis dose. Such studies might also provide important information about the pathophysiological role of peak versus average concentration of uremic toxins.

\section{References}

1 Lowrie EG, Teehan BP: Principles of prescribing dialysis therapy: implementing recommendations from the National Cooperative Dialysis Study. Kidney Int Suppl 1983;S113-S122.

-2 Gotch FA, Sargent JA: A mechanistic analysis of the National Cooperative Dialysis Study (NCDS). Kidney Int 1985;28:526-534.

$\checkmark 3$ Lameire NH, Vanholder R, Veyt D, Lambert MC, Ringoir S: A longitudinal, five year survey of urea kinetic parameters in CAPD patients. Kidney Int 1992;42:426-432.

4 Paniagua R, Amato D, Vonesh E, CorreaRotter R, Ramos A, Moran J, Mujais S: Effects of increased peritoneal clearances on mortality rates in peritoneal dialysis: ADEMEX, a prospective, randomized, controlled trial. J Am Soc Nephrol 2002;13:1307-1320.

5 Eknoyan G, Beck GJ, Cheung AK, Daugirdas JT, Greene T, Kusek JW, Allon M, Bailey J, Delmez JA, Depner TA, Dwyer JT, Levey AS, Levin NW, Milford E, Ornt DB, Rocco MV, Schulman G, Schwab SJ, Teehan BP, Toto R: Effect of dialysis dose and membrane flux in maintenance hemodialysis. N Engl J Med 2002;347:2010-2019.

6 Argyropoulos C, Chang CC, Plantinga L, Fink N, Powe N, Unruh M: Considerations in the Statistical Analysis of Hemodialysis Patient Survival. J Am Soc Nephrol 2009;4: 1779-1786.

7 Li Z, Lew NL, Lazarus JM, Lowrie EG: Comparing the urea reduction ratio and the urea product as outcome-based measures of hemodialysis dose. Am J Kidney Dis 2000;35: 598-605.

$>8$ Lowrie EG, Chertow GM, Lew NL, Lazarus JM, Owen WF: The urea [clearance $\times$ dialysis time] product $(\mathrm{Kt})$ as an outcome-based measure of hemodialysis dose. Kidney Int 1999;56:729-737.
9 Lindholm B, Waniewski J, Werynski A: KT/V: the denominator dilemma. Pol Merkur Lekarski 2003;15:311-315.

10 Casino FG, Lopez T: The equivalent renal urea clearance: a new parameter to assess dialysis dose. Nephrol Dial Transplant 1996; 11:1574-1581.

11 Henderson LW: Critical interpretation of adequacy parameters in peritoneal dialysis and hemodialysis. Perit Dial Int 1999;19(suppl 2):S38-S44.

$\checkmark 12$ Keshaviah P: The solute removal index - a unified basis for comparing disparate therapies. Perit Dial Int 1995;15:101-104.

13 Daugirdas JT, Depner TA, Greene T, Silisteanu P: Solute-solver: a web-based tool for modeling urea kinetics for a broad range of hemodialysis schedules in multiple patients. Am J Kidney Dis 2009;54:798-809.

14 Gotch FA: The current place of urea kinetic modelling with respect to different dialysis modalities. Nephrol Dial Transplant 1998; 13(suppl 6):10-14.

15 Waniewski J, Debowska M, Lindholm B: Theoretical and numerical analysis of different adequacy indices for hemodialysis and peritoneal dialysis. Blood Purif 2006;24: 355-366.

16 Casino FG: Is Kt/V urea a satisfactory measure for dosing the newer dialysis regimens? Semin Dial 2001;14:18-21.

17 Depner TA: Is Kt/V urea a satisfactory measure for dosing the newer dialysis regimens? Semin Dial 2001;14:9-12.

18 Gotch FA: Kt/V is the best dialysis dose parameter. Blood Purif 2000;18:276-285.

19 Gotch FA: Is Kt/V urea a satisfactory measure for dosing the newer dialysis regimens? Semin Dial 2001;14:15-17.

20 Lowrie EG: The normalized treatment ratio $(\mathrm{Kt} / \mathrm{V})$ is not the best dialysis dose parameter. Blood Purif 2000;18:286-294.
21 Vanholder R, Dhondt AM, Van Biesen W: Is $\mathrm{Kt} / \mathrm{V}$ urea a satisfactory measure for dosing the newer dialysis regimens? Semin Dial 2001;14:12-14

22 Jenkins PG: The illogic of Kt/V. Kidney Int 2009;75:337; author reply 337-338.

$>23$ Waniewski J, Lindholm B: Fractional solute removal and $\mathrm{KT} / \mathrm{V}$ in different modalities of renal replacement therapy. Blood Purif 2004; 22:367-376

24 Casino FG: The EKRc Graph: A simple method to estimate the time-averaged urea clearance. Semin Dial 1999;12:11-14.

-25 Casino FG, Marshall MR: Simple and accurate quantification of dialysis in acute renal failure patients during either urea nonsteady state or treatment with irregular or continuous schedules. Nephrol Dial Transplant 2004;19:1454-1466.

26 Couchoud C, Jager KJ, Tomson C, Cabanne JF, Collart F, Finne P, de Francisco A, Frimat L, Garneata L, Leivestad T, Lemaitre V, Limido A, Ots M, Resic H, Stojceva-Taneva O, Kooman J: Assessment of urea removal in haemodialysis and the impact of the European Best Practice Guidelines. Nephrol Dial Transplant 2009;24:1267-1274.

$>27$ Debowska M, Waniewski J, Lindholm B: Bimodal dialysis: theoretical and computational investigations of adequacy indices for combined use of peritoneal dialysis and hemodialysis. Asaio J 2007;53:566-575.

28 Debowska M, Waniewski J, Lindholm B: An integrative description of dialysis adequacy indices for different treatment modalities and schedules of dialysis. Artif Organs 2007; 31:61-69.

29 Depner TA: Hemodialysis adequacy: basic essentials and practical points for the nephrologist in training. Hemodial Int 2005;9: 241-254. 
30 Leypoldt JK, Cheung AK, Deeter RB, Goldfarb-Rumyantzev A, Greene T, Depner TA, Kusek J: Kinetics of urea and beta-microglobulin during and after short hemodialysis treatments. Kidney Int 2004;66:1669-1676.

>31 Leypoldt JK, Jaber BL, Lysaght MJ, McCarthy JT, Moran J: Kinetics and dosing predictions for daily haemofiltration. Nephrol Dial Transplant 2003;18:769-776.

-32 Verrina E, Brendolan A, Gusmano R, Ronco $\mathrm{C}$ : Chronic renal replacement therapy in children: which index is best for adequacy? Kidney Int 1998;54:1690-1696.

33 Daugirdas JT, Blake G, Ing TS: Handbook of Dialysis. Philadelphia, Lippincott Williams \& Wilkins, 2001.

>34 Earthman C, Traughber D, Dobratz J, Howell W: Bioimpedance spectroscopy for clinical assessment of fluid distribution and body cell mass. Nutr Clin Pract 2007;22:389-405.

-35 Konings CJ, Kooman JP, Schonck M, CoxReijven PL, van Kreel B, Gladziwa U, Wirtz J, Gerlag PG, Hoorntje SJ, Wolters J, Heidendal GA, van der Sande FM, Leunissen KM: Assessment of fluid status in peritoneal dialysis patients. Perit Dial Int 2002;22:683692.

-36 Sarkar SR, Kuhlmann MK, Khilnani R, Zhu F, Heymsfield SB, Kaysen GA, Levin NW: Assessment of body composition in longterm hemodialysis patients: rationale and methodology. J Ren Nutr 2005;15:152-158.

$\checkmark 37$ Schneditz D, Fariyike B, Osheroff R, Levin NW: Is intercompartmental urea clearance during hemodialysis a perfusion term? A comparison of two pool urea kinetic models. J Am Soc Nephrol 1995;6:1360-1370.
38 Schneditz D, Platzer D, Daugirdas JT: A diffusion-adjusted regional blood flow model to predict solute kinetics during haemodialysis. Nephrol Dial Transplant 2009;24:22182224.

39 Depner T, Daugirdas J, Greene T, Allon M, Beck G, Chumlea C, Delmez J, Gotch F, Kusek J, Levin N, Macon E, Milford E, Owen W, Star R, Toto R, Eknoyan G: Dialysis dose and the effect of gender and body size on outcome in the HEMO Study. Kidney Int 2004 65:1386-1394.

40 Lowrie EG, Li Z, Ofsthun N, Lazarus JM: Body size, dialysis dose and death risk relationships among hemodialysis patients. Kidney Int 2002;62:1891-1897.

41 Daugirdas JT, Depner TA, Greene T, Kuhlmann MK, Levin NW, Chertow GM, Rocco MV: Surface-area-normalized Kt/V: a method of rescaling dialysis dose to body surface area-implications for different-size patients by gender. Semin Dial 2008;21:415-421.

-42 Lowrie EG, Li Z, Ofsthun N, Lazarus JM: The online measurement of hemodialysis dose (Kt): clinical outcome as a function of body surface area. Kidney Int 2005;68:13441354

43 Daugirdas JT, Levin NW, Kotanko P, Depner TA, Kuhlmann MK, Chertow GM, Rocco MV: Comparison of proposed alternative methods for rescaling dialysis dose: resting energy expenditure, high metabolic rate organ mass, liver size, and body surface area. Semin Dial 2008;21:377-384

44 Canada-USA (CANUSA) Peritoneal Dialysis Study Group: Adequacy of dialysis and nutrition in continuous peritoneal dialysis: association with clinical outcomes. J Am Soc Nephrol 1996;7:198-207.

-45 Keshaviah PR, Nolph KD, Van Stone JC: The peak concentration hypothesis: a urea kinetic approach to comparing the adequacy of continuous ambulatory peritoneal dialysis (CAPD) and hemodialysis. Perit Dial Int 1989;9:257-260.
46 Suri RS, Garg AX, Chertow GM, Levin NW, Rocco MV, Greene T, Beck GJ, Gassman JJ, Eggers PW, Star RA, Ornt DB, Kliger AS: Frequent Hemodialysis Network (FHN) randomized trials: study design. Kidney Int 2007;71:349-359.

47 Charra B, Terrat JC, Vanel T, Chazot C, Jean G, Hurot JM, Lorriaux C: Long thrice weekly hemodialysis: the Tassin experience. Int J Artif Organs 2004;27:265-283.

48 Depner TA: Benefits of more frequent dialysis: lower TAC at the same Kt/V. Nephrol Dial Transplant 1998;13(suppl 6):20-24.

49 Locatelli F, Buoncristiani U, Canaud B, Kohler H, Petitclerc T, Zucchelli P: Dialysis dose and frequency. Nephrol Dial Transplant 2005;20:285-296.

50 Suri RS, Nesrallah GE, Mainra R, Garg AX, Lindsay RM, Greene T, Daugirdas JT: Daily hemodialysis: a systematic review. Clin J Am Soc Nephrol 2006;1:33-42.

51 Zsom L, Zsom M, Fulop T, Flessner MF: Treatment time, chronic inflammation, and hemodynamic stability: the overlooked parameters in hemodialysis quantification. Semin Dial 2008;21:395-400.

52 Greene T, Daugirdas JT, Depner TA, Gotch F, Kuhlman M: Solute clearances and fluid removal in the frequent hemodialysis network trials. Am J Kidney Dis 2009;53:835844

53 Vartia A: Effect of treatment frequency on haemodialysis dose: comparison of EKR and stdKt/V. Nephrol Dial Transplant 2009;24: 2797-2803. 